Article

\title{
Innovative Procedures to Assess Seismic Behaviour of Existing Structures by Means of Non Linear Static Analysis: Polar Spectrum and Capacity Domains
}

\section{Luigi Petti * and Ivana Marino}

Department of Civil Engineering, University of Salerno, Via Ponte Don Melillo, Fisciano, SA 84084, Italy; E-Mail: imarino@unisa.it

* Author to whom correspondence should be addressed; E-Mail: petti@unisa.it;

Tel.: +39-089-964110; Fax: +39-089-964045.

Received: 3 April 2012; in revised form: 11 June 2012 / Accepted: 25 June 2012 /

Published: 18 July 2012

\begin{abstract}
In the last few years, the need to evaluate the seismic performances of buildings on sustaining strong motion has encouraged the development of simplified non-linear static analyses. Several procedures are available today to assess the behavior of plane-frame systems or plan-regular framed buildings suitable for engineering purposes. Less accurate procedures are instead available for irregular structures. This study introduces new tools to assess the seismic performance of irregular structures by using capacity domains and polar spectra. In particular, the capacity domains, plotted in terms of base shear and node control displacements and obtained by means of static non-linear analyses, lead to the evaluation of the direction of least seismic capacity of the investigated structure. The polar spectrum, instead, leads to taking into account the directivity and site effects of seismic events. In particular, the polar spectrum represents the spectral seismic response evaluated for different in-plan directions.
\end{abstract}

Keywords: non linear static analysis; capacity domains; polar spectrum

\section{Introduction}

As known, the standard analysis for traditional seismic design is Linear Dynamic Procedure (LDP) with assigned response spectrum (Response Spectrum Analysis). More complex procedures, such as 
non-linear time history analysis (NDP), are seldom used because of the difficulties in the definition of an accurate hysteretic model to describe the behaviour of the materials under cyclic actions and the choice of a set of accelerograms that describes the real site conditions. Moreover, as it is well-known, NDP analyses present convergence difficulties and require major computational effort.

Non-linear static analysis is instead becoming the key method to evaluate the seismic response of existing structures. This method, which is able to evaluate the collapse mechanism of structures, is suitable for the analysis of existing structures, including the ones not explicitly designed for seismic actions.

However, non-linear static procedures can lead to unsuitable results when applied to irregular structures because of the difficulties in taking into account dynamic lateral-torsional effects and higher mode effects. As it is known, an asymmetric distribution of mass and stiffness, or of strength in plan, leads to high ductility demand for the elements near the soft or weak edge [1-3]. In recent years, several proposals have been put forward to extend traditional pushover analysis, calibrated on plan systems, to the assessment of three-dimensional models behavior [4-15]. At present no simplified procedure which can adequately account for the torsional behaviour of asymmetric structures has been implemented. The main questions concern the combination of the forces in the two directions, and the best way to consider extra ductility demand for the elements near the edges [16-24].

This report presents and discusses the main results of the new methodology to assess the seismic response of irregular structures by means of capacity domains which allow us to evaluate the direction of least seismic capacity of the investigated buildings and the polar spectrum which represents the seismic demand in the plan. In particular, the capacity domains, represented in terms of strength and displacement capacities, are evaluated using traditional pushover analyses by applying load distributions, triangular and uniform, at different angles in the plan to search for the least seismic-resistant direction. The polar spectrum, instead, is a new spectral representation which is able to investigate the seismic demand of each in-plane direction. In particular, this tool is based on the spatial spectral surface obtained by the spectral seismic response evaluated for different in-plan directions and the in-plan projection is defined "Polar Spectrum".

Both polar spectrum and capacity domains allow researchers to investigate the non-linear seismic capacities of irregular structures. As is well-known, indeed, the collapse conditions for a three-dimensional system are also governed by the spatial features of the seismic event. Therefore, the goal of the presented results is to investigate the seismic behavior of irregular structures by considering the least seismic-resistant directions of the investigated structure and the spatial features of the seismic event.

\section{Description of the Benchmark Structures}

For the scope of this report the benchmark structure proposed in the ReLUIS project (Earthquake Engineering Test Labs Network) is considered [25].

The structure, designed without seismic actions, is a five-storey L-shaped building with RC moment frames in two orthogonal directions, as represented in Figure 1. Details of the benchmark structure are contained in the ReLUIS project. 
Figure 1. Benchmark structure plan.

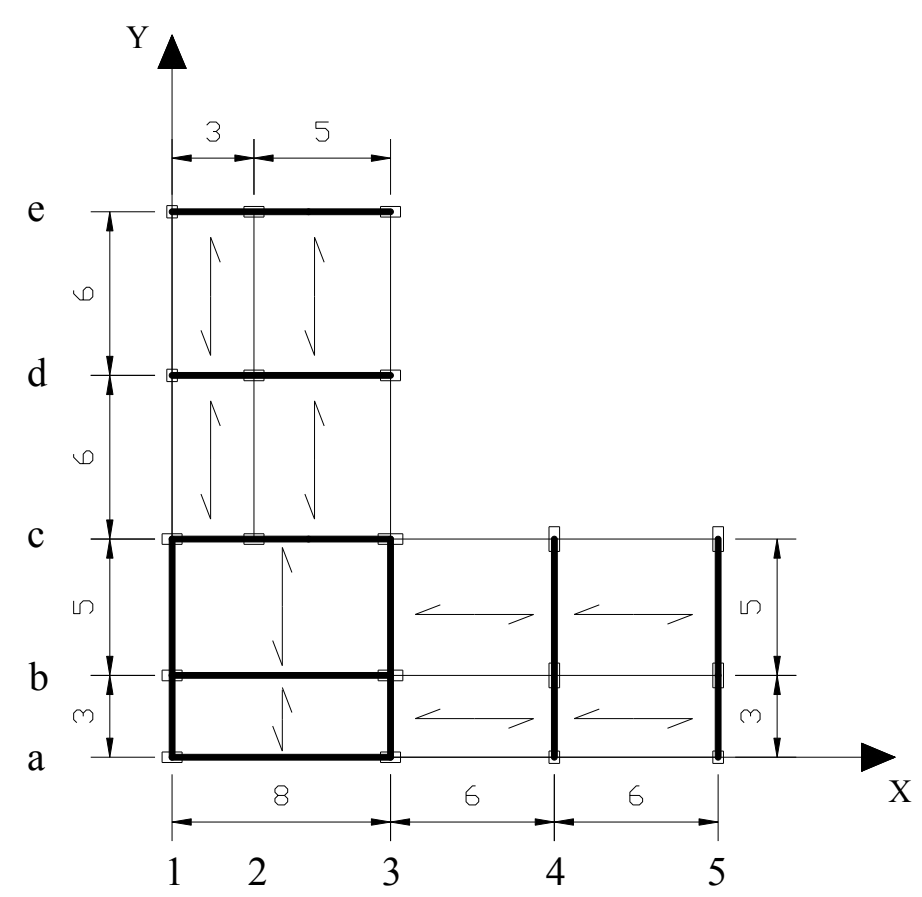

A finite-element model has been implemented in Opensees software [26]. The floors are modeled by means of $50 \mathrm{~mm}$ elastic shells and the elastic modulus is set to the value of 30,000 MPa. Beams and columns are modeled by spread plasticity non-linear elements with fiber sections applied.

The collapse condition for the generic section is defined in terms of section curvature, evaluated by imposing limit strain values for the concrete fibers $\left(\varepsilon_{\mathrm{c}}=0.006\right.$ in compression) and for the reinforced steel fibers ( $\varepsilon_{\mathrm{s}}=0.03$ in tension).

The main dynamical properties of the model are reported in Table 1. In particular, each mode shape is described by the vibration period $(\mathrm{T})$, the mass participation ratios $(\mathrm{M} \%)$ and the sum of the participation ratios up to the considered modal shape (SUM).

Table 1. Modal properties for the Benchmark Structure.

\begin{tabular}{cccccc}
\hline Mode & T(s) & M\%x & M\%y & SumX & SumY \\
\hline 1 & 1.35 & $10.9 \%$ & $52.1 \%$ & $10.9 \%$ & $52.1 \%$ \\
2 & 1.22 & $56.9 \%$ & $19.6 \%$ & $67.8 \%$ & $71.8 \%$ \\
3 & 0.99 & $10.8 \%$ & $9.2 \%$ & $78.6 \%$ & $80.9 \%$ \\
4 & 0.42 & $0.9 \%$ & $8.5 \%$ & $79.4 \%$ & $89.4 \%$ \\
5 & 0.38 & $9.4 \%$ & $1.9 \%$ & $88.8 \%$ & $91.2 \%$ \\
6 & 0.31 & $1.5 \%$ & $1.1 \%$ & $90.3 \%$ & $92.4 \%$ \\
7 & 0.23 & $0.1 \%$ & $4.1 \%$ & $90.4 \%$ & $96.5 \%$ \\
8 & 0.20 & $4.2 \%$ & $0.5 \%$ & $94.6 \%$ & $97.0 \%$ \\
9 & 0.17 & $0.9 \%$ & $0.5 \%$ & $95.5 \%$ & $97.5 \%$ \\
\hline
\end{tabular}

The modal analysis shows a flexible behavior and, moreover, the plan irregularity leads to latero-torsional behaviour for modes 1 and 2 . 


\section{The Concept of Capacity Domains}

In order to assess the non-linear static response of irregular structures it is possible to obtain capacity domains, in terms of control node displacement or base shear. In particular, such domains are obtained from the results of non-linear static procedures (pushover) carried out by varying the in-plan direction of the applied load distribution. The domains, represented in the following, depict the displacement of the control node or the base shear up to collapse.

The analyses are carried out by applying two load distributions along the height of the structure. The first one is a triangular distribution, taking into consideration the inertial masses and the height above the ground. The second one considers only the floor masses. The forces are applied at beam-column joints, proportionally to the joints mass.

For each applied load distribution, 24 capacity curves have been obtained by rotating the direction of action in the $x-y$ plane, $15^{\circ}$ at each step. The control node is assumed to be the centre of mass on the top floor in all the pushover analyses carried out.

Using the described limit values for section curvature, the global collapse is assumed when the first primary element exceeds its limit. Each pushover curve is bi-linearized according to the FEMA 356 procedure [27].

The capacity domains are compared to the non-linear dynamic response to recorded earthquakes, selected among those proposed by ReLUIS [28]. The records, considering both NS and EW components, are suitably scaled to study the structural response by varying ground acceleration as in the case of non linear incremental dynamical analysis.

The main results, for the considered accelerogram, are represented in the following. In particular, Figure 2 refers to the collapse of the analyzed benchmark structure by varying the direction of action in the plan in the case of triangular (TR) and uniform (UN) load distributions and represents the capacity domains. These domains are plotted in terms of displacement of the control node (U) and base shear (Vb). It is possible to observe for both domains a non-regular behaviour of the structure, above all in terms of limit displacements. In particular, the analyses show that the benchmark structure presents lower displacement capacities in the $150^{\circ}-330^{\circ}$ direction. Otherwise, structural behaviour seems to be more regular in terms of strength.

In order to evaluate the applicability of the capacity domains to accurately describe the collapse state of a structure, incremental dynamic analyses have been performed. For both the considered in-plan dispositions of the structures, $0^{\circ}$ and $90^{\circ}$, the analyses have been carried out considering the Iceland 2000 earthquake (code 06334, maximum PGA equal to $7.07 \mathrm{~m} / \mathrm{s} 2$ ). The Figures 3,4 show the dynamic response (NDP) for the analyzed cases. 
Figure 2. (a) Capacity Domains in terms of node control displacements at collapse; (b) Capacity Domains in terms of base shear.

(a)

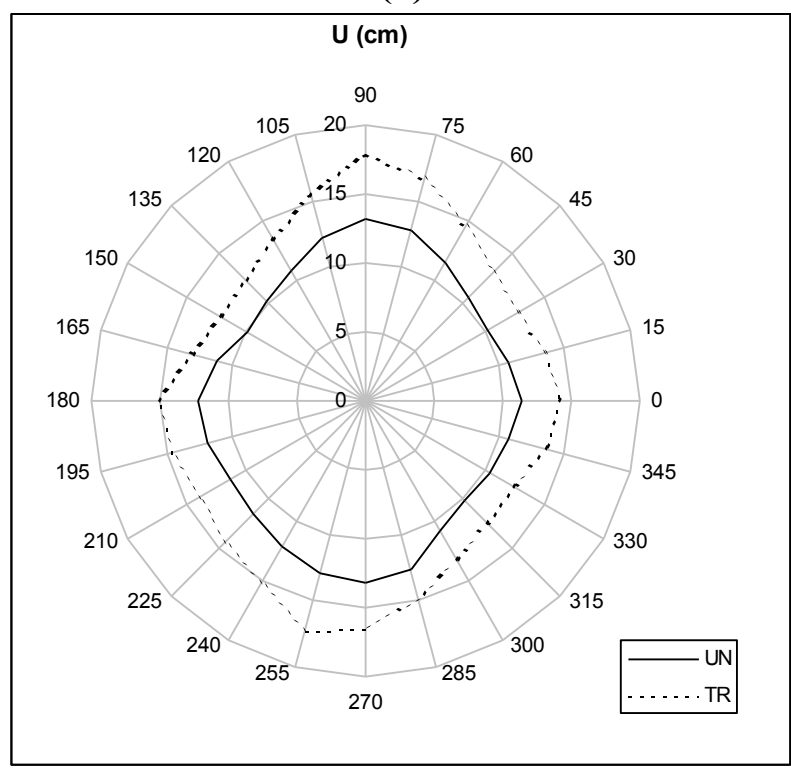

(b)

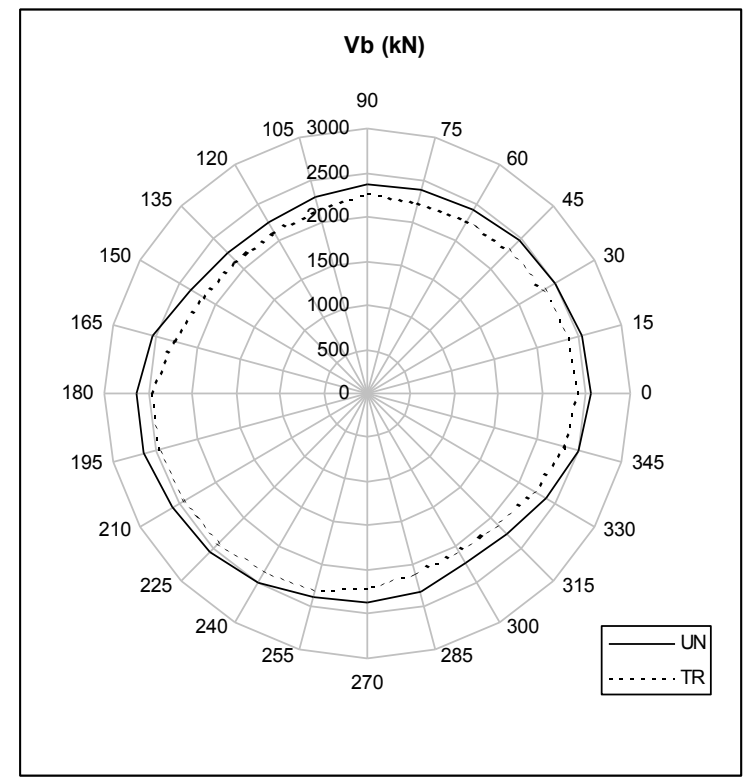

Figure 3. (a) Comparison between capacity domains and NDP-Collapse amplification factor 0.40 -In plan orientation of benchmark structure $0^{\circ}$; (b) Comparison between capacity domains and NDP-Collapse amplification factor 0.40-In plan orientation of benchmark structure $0^{\circ}$.

(a)

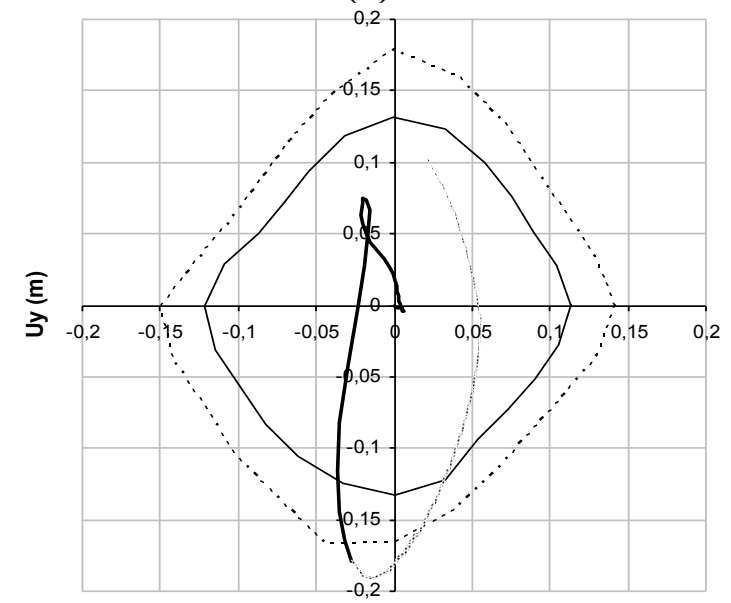

$\mathrm{Ux}(\mathbf{m})$ (b)

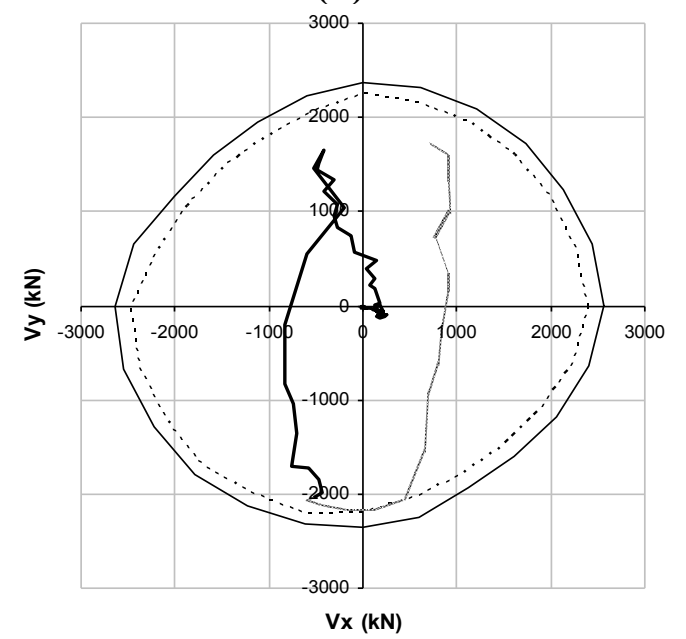

$\mathrm{Vx}(\mathrm{kN})$ 
Figure 4. (a) Comparison between capacity domains and NDP-Collapse amplification factor 0.35-In plan orientation of benchmark structure $90^{\circ}$; (b) Comparison between capacity domains and NDP-Collapse amplification factor 0.35 -In plan orientation of benchmark structure $90^{\circ}$.

(a)

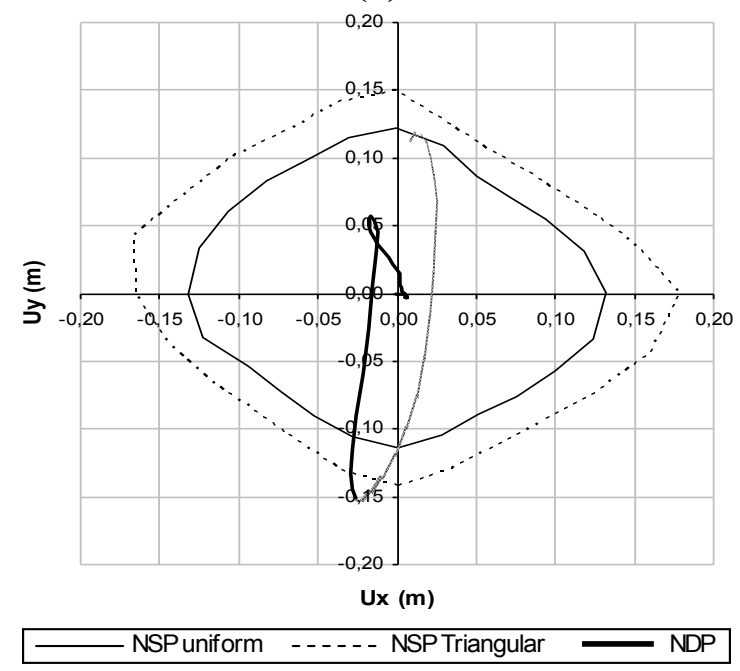

(b)

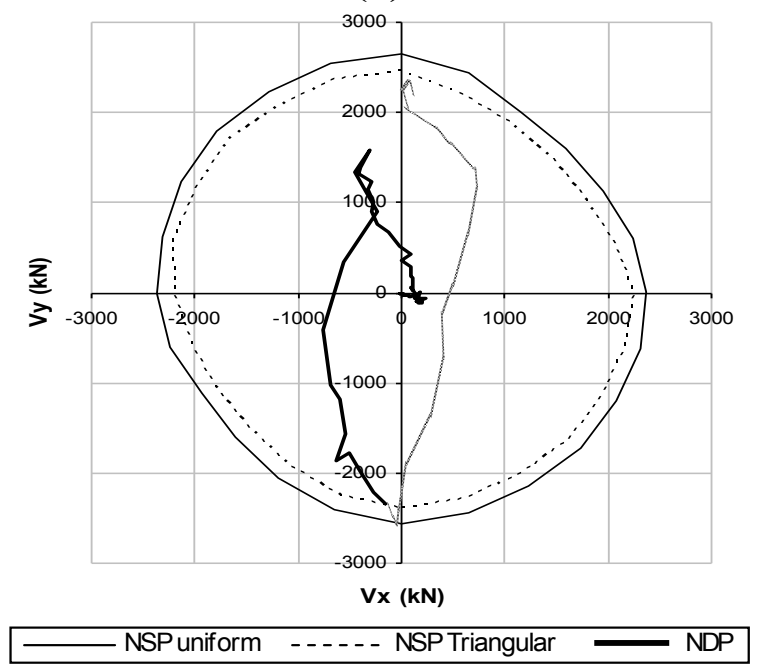

As it is apparent, the collapse is attained in the direction of about $255^{\circ}$ independently of plan orientation of benchmark structure. Moreover, the collapse occurs in correspondence with the capacity domain for triangular load distribution, and the collapsed element, column b-1 (Figure 1), the second column located along the longer side in direction y, at ground level, is the same for both dynamic and static analyses. For both analyses the collapse amplification factor in the case of NDP is represented. In the figures, the capacity domains are indicated with NSP (Non-linear Static Procedure) for the uniform and triangular load distributions.

As a further comparison between static and dynamic responses, Figure 5 shows storey displacements at collapse for both analyses in the considered plan directions of benchmark structure $\left(0^{\circ}\right.$ and $\left.90^{\circ}\right)$.

Results show that the collapse mechanism is a global one, being the displacement path carried out by NDP well described by the one obtained by NSP with triangular load distribution. Moreover, as is apparent, the collapse as well as when read with the NDP procedure always intercepts the capacity domains corresponding to the triangular load distribution (Figures 3,4).

Figure 6 shows the comparison between the behaviour evaluated by means of pushover analyses and that obtained by incremental dynamic analysis. 
Figure 5. (a) Storey Displacement Comparison at collapse for in plan directions $0^{\circ}$; (b) at $90^{\circ}$.

(a)

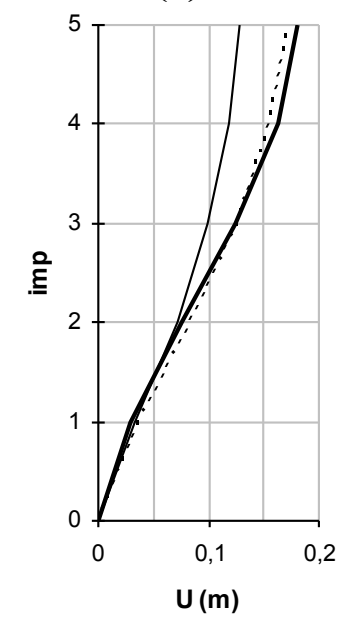

NSP uniform - - - - - NSP Triangular (b)

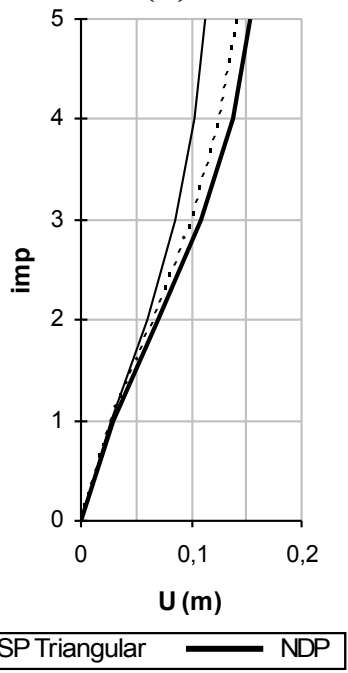

Figure 6. Comparison between Incremental Dynamical Analysis and static non linear analyses-In plan orientation of benchmark structure $0^{\circ}$.

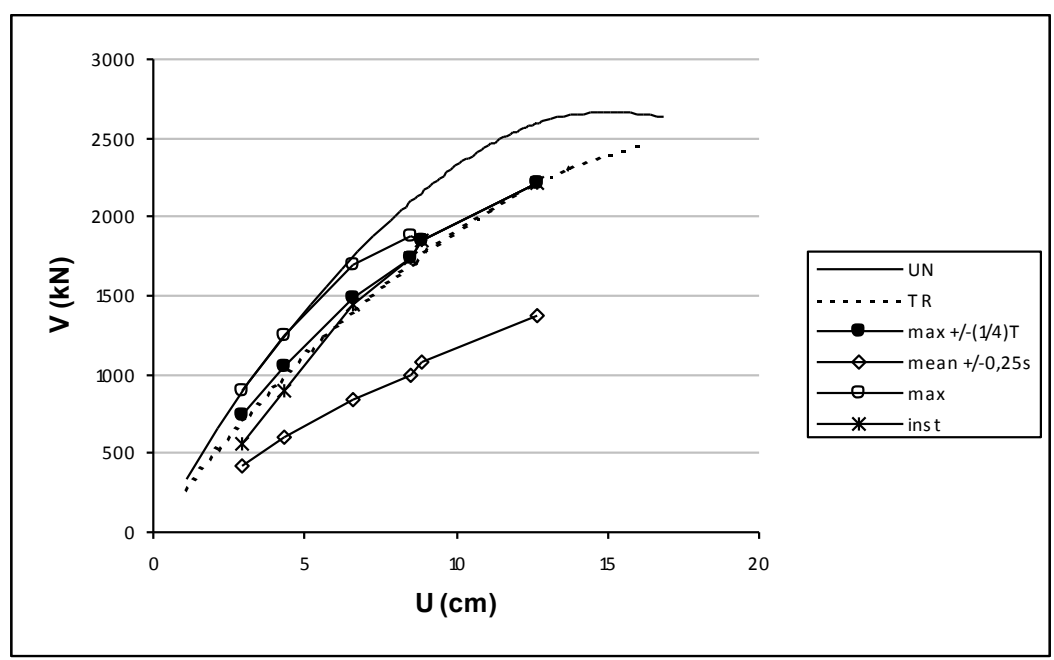

In particular, the figures show the comparison between pushover curves obtained by static non linear analyses in the least resistance direction considering the uniform and triangular load distributions and the pushover curves obtained by incremental dynamic analyses considering several criteria for the graphical representation. Regarding the representation of the time history data, several proposals can be found in the literature [29]. Among these, in the present study, several criteria have been considered: maximum displacement vs. maximum base shear (max), maximum displacement $v s$. corresponding base shear (inst) and maximum displacement $v s$. mean base shear within the interval $+/-0.25 \mathrm{~s}$ (mean $+/-0.25 \mathrm{~s}$ ). Moreover, a new criterion has been proposed herein: the maximum displacement vs. maximum base shear within the interval $+/-(1 / 4) \mathrm{T}(\max +/-(1 / 4) \mathrm{T})$ with $\mathrm{T}$ the dominant natural period of vibration in the direction under examination. The proposed criterion leads to catching the maximum response in a semi-period of oscillation. 
The results (Figures 6 and 7) show that the static non-linear analyses carried out in the least seismic resistant direction will effectively describe the dynamic non-linear response for the investigated structure and considered seismic event. Moreover, the proposed criteria for comparing incremental dynamic and static non linear analysis seems to supply us with the best results for all investigated displacements.

Figure 7. Comparison between Incremental Dynamical Analysis and static non linear analyses-In plan orientation of benchmark structure $90^{\circ}$.

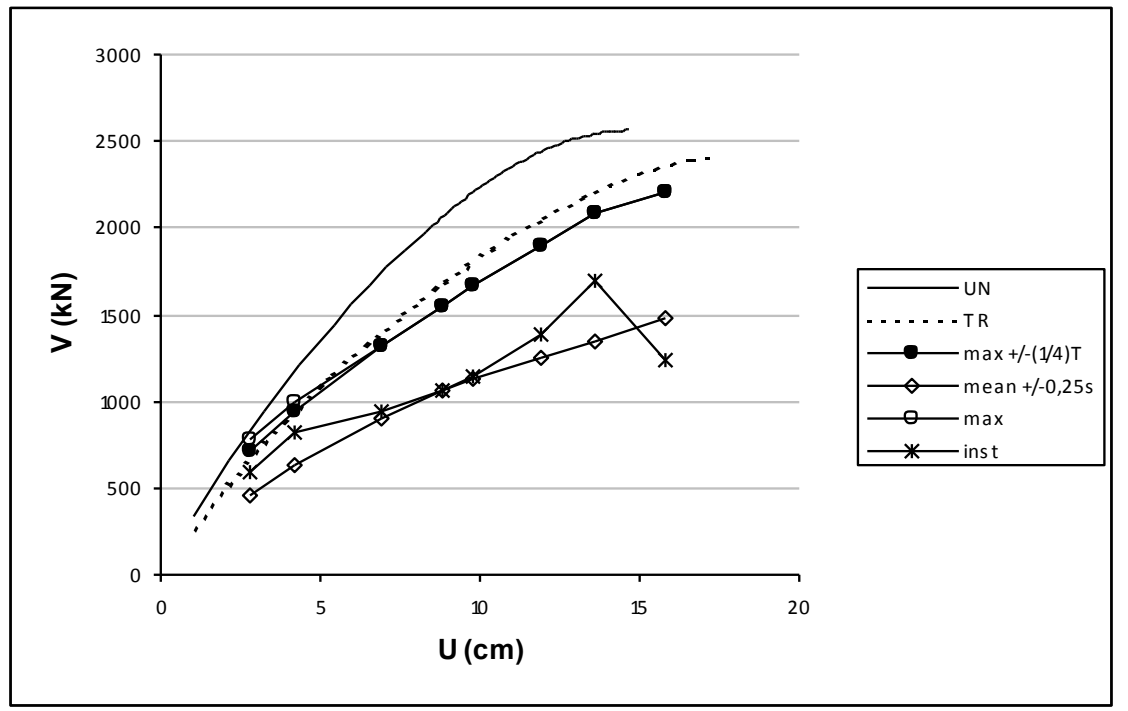

\section{The Concept of Polar Spectrum}

As is known, seismic events generally present strong directivity effects due to site geo-morphological conditions, the source mechanism and the path from the source to the site of the seismic waves.

To take into account the directivity and site effects it is possible to consider the polar spectrum, a new tool, proposed by the authors, which is able to investigate each in-plan direction. In particular, this tool is based on the spatial spectral surface obtained by the spectral seismic response evaluated for different in-plan directions. The in-plan projection of this surface is defined "Polar Spectrum".

Figure 8 shows the polar spectrum in terms of pseudo-acceleration for the seismic event South Iceland aftershock (code 006334) with a damping factor $\xi=0.05$ in the range of periods 0-2 seconds. The polar spectrum represents the projection on the horizontal plan of the spectral surface obtained by evaluating the spectra in each horizontal direction by considering the ground acceleration time histories only in these directions. For the scope, of each considered direction the accelerograms were evaluated by considering the NS and EW recorded components of the seismic event. Each radius of the polar spectrum thus represents, the response evaluated in that direction and each circumference, instead, the spectral demand for a fixed period in each direction. The origin corresponds to a $0 \mathrm{sec}$ period. As it is easy to observe, the polar spectrum is a polar-symmetric figure. 
Figure 8. Polar Spectrum in terms of pseudo-acceleration for the South Iceland aftershock (code 006334).

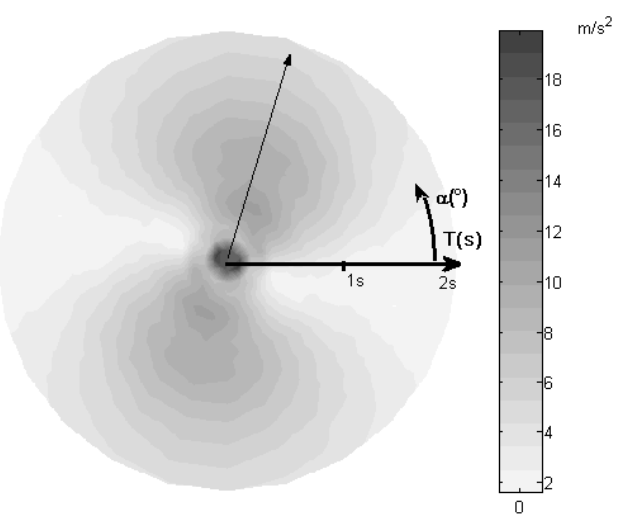

The analysis of the polar spectrum shows that the considered seismic event presents a peak demand along the direction $\left(75^{\circ}-255^{\circ}\right)$ regardless of the vibration period value.

The comparison between the polar spectrum of the considered seismic event and the results of Non-Linear Dynamic Procedure (NDP) is shown clearly, as the collapse of the benchmark structure is controlled in this case by the directivity effects more than by the seismic capacity of the analyzed structure.

\section{Critical Alignment}

The possibility of evaluating the worst structural response moving from observation of the polar spectrum suggests performing dynamic analyses with the structure oriented so that its least capacity direction (assessed by means of the capacity domains) is aligned with the maximum seismic demand (evaluated by means of the polar spectrum).

Figure 9 depicts the results in this case. In particular, the structure has been rotated $105^{\circ}$ counter-clockwise in order to match the least resistant direction $\left(\alpha=150^{\circ}-330^{\circ}\right)$ with the maximum spectral seismic demand direction $\left(75^{\circ}-255^{\circ}\right)$.

Figure 9. Dynamic analyses results, in plan orientation of the benchmark structure $105^{\circ}$, NDP collapse amplification factor 0.30 .

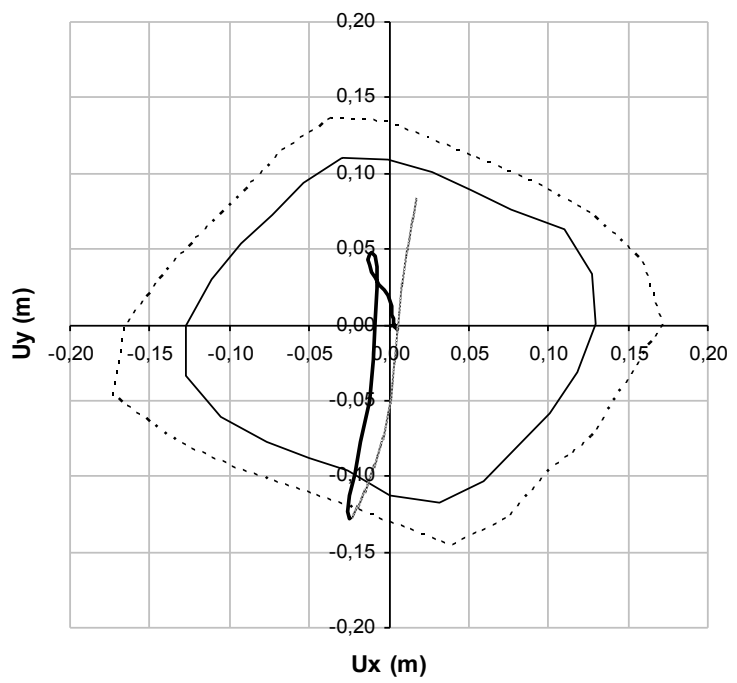


The obtained results show that when the least seismic resistance direction is aligned with the maximum seismic demand, the minimum collapse amplification factor is reached.

\section{Conclusions}

In the field of seismic engineering, an existing open issue is the need to define a feasible procedure to evaluate the seismic performance of irregular structures. In this article, new tools, devised in order to assess the non-linear behaviour of an irregular building and the spectral seismic demand in the plan, have been presented. In particular, capacity domains are evaluated by means of pushover analyses by varying the load distribution in the plan and lead to the search for less seismic resistant directions. The polar spectra lead to full assessment of the spatial features of the seismic demand and represent an opportunity to investigate thoroughly the seismic demand and the event characteristics, being able to clearly evaluate directivity and site effects.

The results, for the investigated structure and the considered earthquake, show that the collapse condition, assessed by means of non linear dynamic procedures, turns out to be coherent with the capacity domains based on the results of traditional non linear procedures carried out by varying the angle of the application of the load distribution.

The non-linear dynamic analyses have shown that the directional components of the seismic event govern the collapse direction. Therefore, the worst condition for an investigated structure is obtained by aligning its least resistance capacity direction, evaluated on the basis of the capacity domains, with the maximum response demand direction identified by the polar spectrum.

Moreover, the study proposes a new criterion to compare incremental dynamic and static non linear analysis which seems to supply the best results for all investigated cases.

\section{References}

1. Fajfar, P.; Marusic, D.; Perus, I. Torsional effects in the pushover-based seismic analysis of buildings. J. Earthq. Eng. 2005, 9, 831-854.

2. Kan, C.L.; Chopra, A.K. Linear and Nonlinear Earthquake Responses of Simple Torsionally Coupled Systems; University of California: Berkeley, CA, USA, 1979.

3. Hejal, R.; Chopra, A. Earthquake Response of Torsionally-coupled Buildings; University of California: Berkeley, CA, USA, 1987.

4. Ayala, A.G.; Tavera, E.A. A new approach for the evaluation of the seismic performance of asymmetric buildings. In Proceedings of the 7th National Conference on Earthquake Engineering, Boston, MA, USA, 21-25 July 2002.

5. Bhatt, C.; Bento, R. Extension of the CSM-FEMA440 to plan-asymmetric real building structures. J. Earthq. Eng. Struct. Dyn. 2011, 40, 1263-1282.

6. Chopra, A.K.; Goel, R.K. A modal pushover analysis procedure to estimate seismic demands for unsymmetric-plan buildings. Earthq. Eng. Struct. Dyn. 2004, 33, 903-927.

7. Fajfar, P.; Kilar, V. Simple push-over analysis of asymmetric buildings. Earthq. Eng. Struct. Dyn. 1997, 26, 233-249. 
8. Fajfar, P.; Kilar, V.; Marusic, D.; Perus, I.; Magliulo, G. The extension of the N2 method to asymmetric buildings. In Proceedings of the Fourth Forum on Implications of Recent Earthquakes on Seismic Risk, Technical Report TIT/EERG, 02/1, Tokyo, Japan, 27-29 May 2002.

9. Fajfar, P.; Marusic, D.; Perus, I.; Kreslin, M. The N2 method for asymmetric buildings. In Proceedings of Nonlinear Static Methods for Design/Assessment of 3D Structures, Lisbon, Portugal, 5-6 May 2008.

10. Fujii, K.; Nakano, Y.; Sanada, Y. Simplified nonlinear analysis procedure for asymmetric buildings. In Proceedings of the 13th World Conference on Earthquake Engineering, Vancouver, BC, Canada, 1-6 August 2004.

11. Goel, R.K. Generalized pushover curves for nonlinear static analysis of three dimensional structures. In Proceedings of Nonlinear Static Methods for Design/Assessment of 3D Structures, Lisbon, Portugal, 5-6 May 2008.

12. Kilar, V.; Fajfar, P. On the applicability of pushover analysis to the seismic performance evaluation of asymmetric buildings. Eur. Earthq. Eng. 2001, 15, 20-31.

13. Moghadam, A.S.; Tso, K. Pushover analysis for asymmetric and set-back multistory buildings. In Proceedings of the 12th World Conference on Earthquake Engineering, Auckland, New Zealand, 30 January-4 February 2000; p. 1093.

14. Tso, W.K.; Moghadam, A.S. Seismic response of asymmetrical buildings using pushover analysis. In Proceedings of the International Workshop on Seismic Design Methodologies for the Next Generation of Codes, Bled, Slovenia, 24-27 June 1997.

15. Yu, Q.S.K.; Pugliesi, R.; Allen, M.; Bischoff, C. Assessment of modal pushover analysis procedure and its application to seismic evaluation of existing building. In Proceedings of the 13th World Conference on Earthquake Engineering, Vancouver, BC, Canada, 1-6 August 2004.

16. Pettinga, J.D.; Priestley, M.J.N.; Pampanin, S.; Christopulos, C. The role of inelastic torsion in the determination of residual deformations. J. Earthq. Eng. 2007, 11, 133-157.

17. Zarate, A.; Ayala, A.G. Validation of single storey models for the evaluation of seismic performance of multi-storey asymmetric buildings. In Proceedings of the 13th World Conference on Earthquake Engineering, Vancouver, BC, Canada, 1-6 August 2004.

18. Faella, G.; Kilar, V. Asymmetric multistory R/C frame structures: Push-over versus nonlinear dynamic analysis. In Proceedings of the Eleventh European Conference on Earthquake Engineering, Paris, France, 6-11 September 1998.

19. Rutenberg, A.; Levy, R.; Magliulo, G. Seismic response of asymmetric perimeter frame steel buildings. In Proceedings of the 12th European Conference on Earthquake Engineering, London, UK, 9-13 September 2002.

20. Marino, I.; Petti, L. Seismic assessment of asymmetric structures behaviour by using static non-linear analysis. J. Civ. Eng. Archit. 2011, 5, 401-411.

21. Tso, W.K.; Myslimaj, B. Effect of strength distribution on the inelastic torsional response of asymmetric structural systems. In Proceedings of the 12th European Conference on Earthquake Engineering, London, UK, 9-13 September 2002.

22. Reyes, J.C.; Chopra, A.K. Evaluation of three-dimensional modal pushover analysis for unsymmetric-plan buildings subjected to two components of ground motion. Earthq. Eng. Struct. Dyn. 2011, 40, 1475-1494. 
23. Rutenberg, A. EAEE Task Group (TG) 8: Behaviour of irregular and complex structures asymmetric structures-progress since 1998. In Proceedings of the 12th European Conference on Earthquake Engineering, London, UK, 9-13 September 2002.

24. Petti, L.; Marino, I.; Cuoco, L.; Palazzo, B. Assessment of seismic response of plan-asymmetric structures through simplified static nonlinear analyses. In Proceedings of the 14th World Conference on Earthquake Engineeering, Beijing, China, 12-17 October 2008.

25. ReLUIS project-Earthquake Engineering Test Labs Network Homepage. Available online: http://www.reluis.unina.it (accessed on 25 June 2012).

26. Open System for Earthquake Engineering Simulation Homepage. (OpenSEES). Available online: http://opensees.berkeley.edu/ (accessed on 25 June 2012).

27. FEMA (Federal Earthquake Management Agency) 356. Prestandard and Commentary for the Seismic Rehabilitation of Buildings, [DVD]; FEMA 356: Washington, DC, USA, 2000.

28. European Strong Motion Database Homepage. Available online: http://www.isesd.cv.ic.ac.uk (accessed on 25 June 2012).

29. Chopra, A.K. Application of modal pushover analysis to RC frames and incremental dynamic analysis. In Proceedings of Nonlinear Static Methods for Design/Assessment of $3 D$ Structures, Lisbon, Portugal, 5-6 May 2008.

(C) 2012 by the authors; licensee MDPI, Basel, Switzerland. This article is an open access article distributed under the terms and conditions of the Creative Commons Attribution license (http://creativecommons.org/licenses/by/3.0/). 